\title{
РОЛЬ И МЕСТО СОПУТСТВУЮЩЕГО САХАРНОГО ДИАБЕТА 2 ТИПА В ПРАКТИЧЕСКОЙ ДЕЯТЕЛЬНОСТИ ТЕРАПЕВТИЧЕСКОГО ОТДЕЛЕНИЯ МНОГОПРОФИЛЬНОГО СТАЦИОНАРА
}

\author{
Степанова Д.В., Зарубина Д.Г., Магомедова Д.М., Атдуев К.А., Некрасова Т.А., Стронгин Л.Г.
}

ФГБОУ ВО «Приволжский исследовательский медицинский университет» Минздрава России, Нижний Новгород

ЦЕЛЬ: исследовать распространенность сопутствующего сахарного диабета 2 типа (СД2), его клинические особенности и влияние на течение стационарного периода у госпитализированных больных терапевтического профиля.

МАТЕРИАЛЫ И МЕТОДЫ: В исследование включены все пациенты, госпитализированные в терапевтическое отделение многопрофильного стационара ГКБ №5 Нижнего Новгорода с 01.01.2016 г. по 31.06.2016 г. Всего проанализировано 529 историй болезни пациентов с различными основными диагнозами, в том числе с острой пневмонией (ОП), хронической обструктивной болезнью легких (ХОБЛ), бронхиальной астмой (БА), ишемической болезнью сердца (ИБС), артериальной гипертензией (АГ), циррозом печени и другими нозологиями. Из них 152 человека имели сопутствующий СД2. Средний возраст

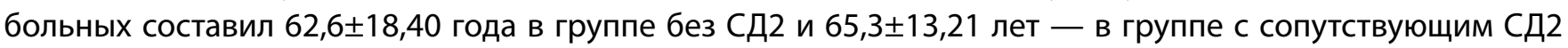
(р>0,05). Проводилась ретроспективная оценка клинических и биохимических показателей, уровней гликемии и гликированного гемоглобина (HbA1c), потребности в консультациях эндокринолога и длительности пребывания в стационаре. Для сравнения групп применялись методы Манна-Уитни и Хи-квадрат, данные представлены в виде среднего и стандартного отклонения.

РЕЗУЛЬТАТЫ: сопутствующий СД2 широко распространен среди больных терапевтических отделений многопрофильных стационаров (28,7\% пациентов). Его распространенность среди лиц с основным диагнозом АГ составляет 22,5\%, ИБС - 26,6\%, ОП - 16,1\%, БА - 25\%, ХОБЛ - 22,1\%, цирроз печени - 33,3\%. Больные с сочетанной патологией являются сложными пациентами, в том числе в связи с более высокой коморбидностью и частой ассоциацией с сердечно-сосудистыми заболеваниями. Среди них значимо больше лиц с сопутствующей АГ ( $p=0,0001)$ и острыми нарушениями мозгового кровообращения в анамнезе $(p=0,007)$. На догоспитальном этапе большинство пациентов с сочетанной патологией не уделяют

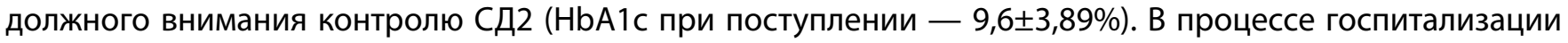
лечащий врач привлекает эндокринолога к лечению пациента с сочетанной патологией в $67,1 \%$ случаев, что обычно касается лиц с достоверно худшей компенсацией углеводного обмена по показателям гликемии ( $p=0,000001)$ и HbA1c $(p=0,005)$. У пациентов, осмотренных эндокринологом, чаще происходят оптимизация пероральной сахароснижающей терапии ( $(=0,041)$, а также инициация инсулинотерапии с ее продолжением в постгоспитальном периоде (22,5\% случаев), что в перспективе должно положительно сказаться на течении заболевания и риске осложнений.

Выводы: госпитальный период лечения терапевтических больных с сопутствующим СД2 может быть использован для оптимизации лечения эндокринной патологии, что актуально в свете широкой распространенности СД2 среди пациентов терапевтических отделений, зачастую неудовлетворительной компенсации нарушений углеводного обмена на догоспитальном этапе, высокой нуждаемости больных в оптимизации пероральной сахароснижающей терапии и инициации инсулинотерапии.

КЛЮЧЕВЫЕ СЛОВА: сахарный диабет; распространенность; сочетанная патология; терапевтические больные. 